\title{
Promovendo a compreensão de textos em estudantes alfabetizados na infância e na idade adulta
}

\section{Promoting reading comprehension in literate students in childhood and adulthood}

\author{
Andrea Giglio Bottino ${ }^{1}$ \\ Thamires de Abreu Emmerick ${ }^{2}$ \\ Adriana Benevides Soares ${ }^{3}$
}

\begin{abstract}
RESUMO
Este estudo propõe uma análise e comparação do processo de compreensão de textos em alunos alfabetizados na idade adulta e alunos alfabetizados na infância. Participaram desta pesquisa 49 alunos adultos alfabetizados, do sexo masculino, com idade superior a 18 anos, frequentadores de instituições públicas ou privadas. Sendo que 29 universitários foram alfabetizados na infância $(\mathrm{AC})$ e os outros 20 foram alunos alfabetizados na idade adulta (AA), sendo frequentadores do primeiro segmento do ensino fundamental, de classes de educação de jovens e adultos. Foram realizadas três etapas: no pré-teste, ambos os grupos, após a leitura de um texto, responderam um questionário e somente aqueles que obtiveram menos de $50 \%$ de acertos participaram da intervenção e do pós-teste. Na etapa da intervenção, os leitores menos habilidosos elaboraram um roteiro para a melhoria da compreensão de textos com a orientação do pesquisador. No pós-teste, esses mesmos participantes responderam um novo questionário, após a leitura de um novo texto. As comparações entre os resultados do pré e pós-teste mostraram que os leitores menos habilidosos melhoraram seus desempenhos nos níveis de compreensão textual, principalmente na macroestrutura e na argumentação.

Palavras-chave: compreensão de textos; linguagem; alunos leitores.
\end{abstract}

1 Pedagoga. Doutora em Psicologia pela Universidade Federal do Rio de Janeiro. Professora da graduação da Universidade Veiga de Almeida (UVA) e professora da graduação da Faculdade de Filosofia, Ciências e Letras de Macaé (FAFIMA). Brasil. E-mail: agbottino@gmail.com

2 Estudante de Graduação em Psicologia - Universidade do Estado do Rio de Janeiro - Brasil. E-mail: thataemmerick@hotmail.com

3 Psicóloga. Doutora em Psicologia pela Universidade de Paris XI. Professora da graduação e da pós-graduação da Universidade Salgado de Oliveira e docente da graduação da Universidade do Estado do Rio de Janeiro - Instituto de Psicologia Universidade do Estado do Rio de Janeiro Brasil. E-mail: adribenevides@gmail.com 


\begin{abstract}
This study proposes an analysis and comparison of the reading comprehension process in literate students who learned literacy when adults and those who learned literacy when they were children. A total of 49 students participated in this research: literate adults, male, aged over 18 years, attending public or private institutions. From those, 29 students became literate while children (group AC) and the other 20 were students who became literate when adults (group AA) that were attendants of the first segment of an elementary school class for the youth and adults. There were three stages: the pre-test, in which both groups after reading a text, answered a questionnaire and only those who were less than $50 \%$ correct participated in the intervention and post-test. In the intervention stage, low skilled readers produced a roadmap to improve the understanding of texts under the researcher guidance. In the post-test, these same participants answered a new questionnaire after reading a new text. The comparisons between the results of pre- and post-test showed that the low skilled readers improved their performance levels in reading comprehension, especially in the macrostructure and argumentation.
\end{abstract}

Keywords: texts understanding; language; reader students.

\title{
Introdução
}

Compreender um texto implica envolver processos perceptivos, mnemônicos, inferenciais, dedutivos e de processamento estratégico. A leitura constitui-se como uma atividade cognitiva por excelência. Portanto, ler é extrair significado, sendo a compreensão o propósito básico da aprendizagem da leitura (ANDRADE; DIAS, 2006).

Segundo McNamara (2007), um dos modelos de compreensão de maior repercussão na literatura procura explicar como as informações textuais e as informações derivadas do conhecimento de mundo do leitor se integram e se conectam em uma representação mental coerente. O modelo de maior aceitação na área é o Modelo de Construção Integração (CI), de Kintsch (1998). Este modelo focaliza o conhecimento de mundo do receptor de texto, os elementos textuais (conteúdo e forma linguística) e a interação entre esses aspectos, especificando duas fases durante o processo de compreensão: a fase de construção e a fase de integração.

$\mathrm{Na}$ fase de construção, um modelo mental é construído gradativamente a partir do significado das palavras e proposições. Já a fase de integração é de natureza local e global, e ocorre sempre que uma nova informação é adicio- 
nada, permitindo a construção de sentidos com base nas antigas informações e nas novas informações. Ao realizar este processo, o leitor integra informações veiculadas no texto (representação mental que corresponde fortemente ao textobase) e também integra essas informações com seu conhecimento de mundo (representação mental que corresponde às elaborações do leitor, denominada modelo situacional) (SPINILLO; MAHON, 2007).

Nesse modelo, de acordo com Kintsch (1993), há três níveis hierárquicos distintos de representação: o nível de superfície, o proposicional e o mais elaborado. No nível de superfície não há uma total interação entre autor e leitor. Neste caso, o leitor apresenta dificuldades em descobrir qual sentido o autor quis dar ao texto. O nível proposicional é chamado por Kintsch de base do texto, pois constitui o conteúdo semântico coerente do texto. O nível mais elaborado, também chamado de modelo da situação, integra o conteúdo semântico do texto em uma estrutura de conhecimento ou esquema.

Segundo Van Dijk e Kintsch (1983), a capacidade de compreensão textual envolve tanto a leitura como a percepção auditiva, e pode ser observada em leitores que decodificam com bastante facilidade e também em leitores que precisam dedicar mais recursos e tempo para a decodificação. Em seu modelo de operações, a superfície da estrutura de um discurso é interpretada como um conjunto de proposições, dentro deste conjunto há uma série de relações semânticas. Neste modelo distinguem-se três níveis de compreensão: a Macroestrutura, caracterizada como a estrutura geral do texto; a Argumentação, que é a explicação, a justificativa, o raciocínio que o autor segue para chegar ao tema; os Detalhes, a parte do texto que está como suplemento, acrescentando ideias sem maior importância para compreensão do texto. Além desses três níveis, também pode-se destacar a Inferência, que diz respeito às questões fora do texto, que necessitam de conhecimentos prévios de mundo do leitor.

Para esses autores, a estrutura semântica do discurso deve ser caracterizada em termos de um texto-base, como uma unidade coerente e estruturada. Um discurso pode ser chamado de um texto-base explícito, ou seja, que apresenta proposições claras que não dependem de outras informações do leitor, ou um texto-base implícito, que podem ser providos perfeitamente pelo leitor.

Ainda sobre os diferentes níveis de compreensão de um texto, é necessário mencionar que a representação mental do texto deve-se organizar como um todo coerente. Vilaseca (1999) procura abordar o problema da compreensão e memória com especial ênfase no que diz respeito à macroestrutura. $\mathrm{O}$ processo de compreensão tem um caráter construtivo, que pode ser descrito como a construção de uma estrutura capaz de apreender as relações semânticas que se estabelecem entre a entrada textual e os conhecimentos prévios, que são recupe- 
rados na memória ao longo do processamento. O resultado final desse processo de construção é uma representação proposicional do texto que inclui, por um lado, as proposições que se formam diretamente a partir da entrada textual, e por outro, de uma série de conceitos relevantes e irrelevantes.

Embora a macroestrutura seja crucial para a compreensão de um texto, compreender textos é também um processo inferencial por excelência (SPINILLO; MAHON, 2007). Uma vez que nem tudo está explicitado no texto, o estabelecimento de inferências se torna uma atividade essencial, um processo de alto nível responsável pela formação de sentidos e de uma representação mental organizada e coerente do texto, resgatando a não explicitude das informações nele vinculadas. Para Spinillo e Mahon (2007), as inferências preenchem as lacunas deixadas pelo autor, de forma que o texto pode ser entendido como algo inacabado, cujo significado é o produto de uma coautoria.

É fato que há inúmeros processos que levam à compreensão de textos e não é em vão que existem muitos trabalhos que são relevantes na dinâmica do estudo acerca deste tema (DIAS; ROAZZI; RODRIGUES, 2002; SANTOS; SILVA, 2004; OLIVEIRA; SUHEIRO; SANTOS, 2004; BARIANI; MARTINS; SANTOS, 2005; OLIVEIRA; SANTOS, 2005; CUNHA; SANTOS, 2006).

É possível constatar que as pesquisas cognitivistas sobre compreensão de textos, de forma geral, têm se concentrado na descrição e organização do conteúdo proposicional, com constante ênfase nas dificuldades inerentes a este processo. Sendo assim, debruçar-se sobre o estudo acerca do processo de alfabetização, quando, supostamente, inicia-se o contato com o cotidiano textual, considerando a faixa etária em que este processo ocorre, torna-se indispensável.

Na Tele-Conferência sobre Alfabetização (2001) foi relatado que metade das crianças brasileiras que estão atualmente na escola pública não consegue se alfabetizar na $1^{a}$ série, precisando o Brasil mudar essa situação. Caso não seja possível reverter esta questão em breve, provavelmente esses alunos, que são crianças hoje, serão futuros frequentadores de escolas supletivas, atendendo, assim, a mais essa demanda, a Educação de Jovens e Adultos no Brasil. Esta clientela, quase que na sua totalidade, já é constituída por alunos que fracassaram no ensino regular e por aqueles que não tiveram a oportunidade de estudar enquanto crianças, devido ao ingresso antecipado no mercado de trabalho, precisando ser mais um membro a contribuir com o orçamento da família.

Para Ferreiro (2001), o Brasil é um país que passa por várias Revoluções: a Revolução da Informática, da Tecnologia e da Comunicação, mas mesmo assim, diante de grandes avanços, de grande modernidade, tanto o analfabeto como o analfabeto funcional continuam existindo no contexto social do país. O grande 
desafio é a alfabetização, é fazer com que o aluno aprenda, compreenda, leia e escreva tornando-se sujeito de sua própria história.

Outros autores, como Freire (2002) e Ribeiro (1999), ressaltam a importância dos processos de aquisição da leitura e da escrita para a formação da cidadania. Segundo esses autores, para se formar um cidadão, é necessário que haja um melhor entendimento do processo de compreensão da linguagem escrita na Educação de Jovens e Adultos, havendo, portanto, a possibilidade do sujeito entender melhor o mundo que o cerca. Um bom desempenho da linguagem proporciona uma melhor comunicação, como também possibilita ponderar diferentes situações. Nesse viés, Sternberg (2000) sustenta que a linguagem é um meio organizado de combinar as palavras para fins de comunicação, possibilitando que esta aconteça entre as pessoas, ponderando diversas situações e processos.

No âmbito da Educação com Jovens e Adultos, é importante considerar que o professor engajado neste trabalho se vê repentinamente diante de uma população adulta, cujo atendimento exigiria um preparo adequado, até então inexistente ao sistema regular de ensino brasileiro. Além do despreparo do professor, inúmeras dificuldades administrativas, pedagógicas e psicológicas agravam a problemática da Educação de Jovens e Adultos, como a carência de material didático apropriado, falta de escola perto do local de trabalho, ou até mesmo dentro do próprio espaço de trabalho, medo da escola e da professora, falta de orientação psicológica, ausência de qualidade de vida e outros tantos entraves.

Esse quadro crítico, que reflete as limitações e dissonâncias da Educação em nosso país, tem levado a sérios questionamentos. Que fazer, no âmbito da sala de aula, para minimizar tais problemas? Como atender de forma adequada à Educação Popular, que já está engajada no mercado de trabalho? Como facilitar a aprendizagem daqueles que, por algum motivo, não tiveram a oportunidade de ingressar no ensino regular e se veem marginalizados, oprimidos pela sociedade? Como proporcionar uma melhor compreensão de textos para esses Jovens e Adultos no âmbito da sala de aula?

Diante desses questionamentos, é que neste estudo buscou-se identificar as dificuldades que se apresentam durante o processo de compreensão, tanto em um público que foi alfabetizado tardiamente quanto naqueles que aprenderam a ler e escrever na infância, promover a compreensão daqueles que apresentam deficiências através da formalização de estruturas textuais que deverão servir de guias para a organização mental do sujeito.

Sendo assim, o objetivo deste trabalho é analisar a compreensão de textos de estudantes comparando aqueles que foram alfabetizados na infância e os que foram alfabetizados na fase adulta. 


\section{Metodologia}

\section{Participantes}

Os 49 participantes desta pesquisa foram adultos alfabetizados, do sexo masculino, com idade superior a 18 anos, frequentadores de instituições públicas ou privadas. 29 alunos universitários, que foram alfabetizados durante a infância, compuseram o primeiro grupo (AC), e os outros 20 alunos, que foram alfabetizados na idade adulta (grupo AA), são frequentadores do primeiro segmento do ensino fundamental, de classes de Educação de Jovens e Adultos.

\section{Instrumentos}

Questionário para os participantes - coleta de dados sociodemográficos e também dados sobre hábitos e frequência de leitura dos sujeitos.

Dois textos diferentes, ambos contemplando 20 (vinte) perguntas, sendo 07 (sete) questões referentes à macroestrutura; 06 (seis) referentes à argumentação; 04 (quatro) questões sobre inferências e 03 (três) referentes a detalhes. $\mathrm{O}$ primeiro texto utilizado intitulava-se $O$ Ato de Estudar (FREIRE, 2002, adaptado por BOTTINO, 2004), contendo 390 (trezentos e noventa) palavras, 28 (vinte e oito) frases e 08 (oito) parágrafos; e, o segundo, intitulado A Mulher no Mercado de Trabalho (BRASIL, 1998), contendo 479 (quatrocentos e setenta e nove) palavras, 25 (vinte cinco) frases e 12 (doze) parágrafos.

\section{Procedimentos}

Inicialmente, foi assinado o termo de consentimento livre e esclarecido por todos os participantes voluntários da pesquisa, para que tomassem ciência dos objetivos e das atividades que foram propostas ao longo deste estudo.

A pesquisa foi desenvolvida em três etapas: pré-teste, intervenção e pós-teste. A primeira etapa consistiu de um pré-teste para ambos os grupos. Receberam o texto $O$ Ato de Estudar, para que cada sujeito lesse e respondesse seu questionário associado.

A segunda etapa, a de intervenção, foi composta apenas pelos leitores menos habilidosos de ambos os grupos, ou seja, aqueles que obtiveram menos de $50 \%$ de acertos nas questões referentes ao texto $O$ Ato de Estudar. Este novo grupo foi composto por, no mínimo, 15 sujeitos para ambos os grupos iniciais. 
Para este novo grupo, foi proposto, primeiro, com a orientação do pesquisador, a elaboração de um roteiro explicativo (guia) sobre o texto $O$ Ato de Estudar, que evidenciava quais partes do texto compunham a macroestrutura, a argumentação, os detalhes e quais inferências eram esperadas para a compreensão daquele texto.

A terceira etapa da pesquisa, o pós-teste, consistiu na leitura de um novo texto, A Mulher no Mercado de Trabalho, e a resposta de um questionário associado a ele. Ao final desta terceira etapa, foi analisado o percentual de acertos referente às questões, comparando se os leitores menos habilidosos tiveram um melhor êxito na compreensão da linguagem escrita ao responderem o questionário, após a explicação de cada parte do roteiro e o uso do mesmo.

O grupo de controle, formado pelos leitores mais habilidosos, realizou apenas o pré-teste, para que esse servisse como ponto de referência ao longo de toda a pesquisa. Após a realização do pós-teste, pelos leitores menos habilidosos, foi realizada uma análise, comparando se os leitores menos habilidosos obtiveram avanços significativos a ponto de se tornarem ou se aproximarem do desempenho dos leitores mais habilidosos.

\section{Apresentação dos Resultados}

A Tabela 1 compara as médias obtidas pelos participantes no pré-teste e no pós-teste.

TABELA 1 - MÉDIAS OBTIDAS NO PRÉ E NO PÓS-TESTE PELOS GRUPOS

\begin{tabular}{c|c|c|c|c|c|c|c|c}
\hline & & \multicolumn{2}{|c|}{ Pré-teste } & & \multicolumn{2}{c|}{ Pós-teste } & & \\
\hline & N & Média & DP & & Média & DP & $\boldsymbol{t}$ & \\
\hline AA & & & & & & & & \\
\hline Macroestrutura & 15 & 0,07 & 0,08 & & 0,65 & 0,19 & $-10,57$ & $*$ \\
\hline Argumentação & 15 & 0,23 & 0,18 & & 0,72 & 0,19 & $-8,05$ & $*$ \\
\hline Inferência & 15 & 0,72 & 0,23 & & 0,57 & 0,20 & 2,81 & $*$ \\
\hline Detalhes & 15 & 0,91 & 0,20 & & 0,87 & 0,25 & 0,56 & \\
\hline Total & $\mathbf{1 5}$ & $\mathbf{0 , 4 0}$ & $\mathbf{0 , 0 7}$ & & $\mathbf{0 , 6 9}$ & $\mathbf{0 , 0 9}$ & $\mathbf{- 9 , 1 5}$ & $*$ \\
\hline
\end{tabular}


TABELA 1 - MÉDIAS OBTIDAS NO PRÉ E NO PÓS-TESTE PELOS GRUPOS

conclusão

\begin{tabular}{c|c|c|c|c|c|c|c|c}
\hline & & \multicolumn{2}{|c|}{ Pré-teste } & \multicolumn{2}{|c|}{ Pós-teste } & & \\
\hline & $\mathbf{N}$ & Média & $\mathbf{D P}$ & & Média & $\mathbf{D P}$ & $\boldsymbol{t}$ & \\
\hline AC & & & & & & & & \\
\hline Macroestrutura & 18 & 0,36 & 0,17 & & 0,68 & 0,21 & $-4,69$ & $*$ \\
\hline Argumentação & 18 & 0,19 & 0,13 & & 0,78 & 0,11 & $-14,25$ & $*$ \\
\hline Inferência & 18 & 0,65 & 0,21 & & 0,78 & 0,23 & $-1,53$ & \\
\hline Detalhes & 18 & 0,78 & 0,28 & & 0,96 & 0,11 & $-3,34$ & $*$ \\
\hline Total & $\mathbf{1 8}$ & $\mathbf{0 , 4 5}$ & $\mathbf{0 , 0 8}$ & & $\mathbf{0 , 7 7}$ & $\mathbf{0 , 0 9}$ & $\mathbf{- 1 0 , 5 4}$ & $*$ \\
\hline
\end{tabular}

$* \mathrm{p}<0,05$.

No pré-teste, o grupo AA apresentou diferenças significativas entre o pré e o pós-teste no escore total e em todas as estruturas do texto, com exceção do nível de detalhes. No grupo AC também foram encontradas diferenças significativas no escore total e nos níveis de macroestrutura, argumentação e detalhes.

\section{Discussão}

Quanto aos resultados relativos à comparação entre pré-teste e pós-teste, os dados sinalizam que tanto o grupo dos leitores alfabetizados na infância quanto os alfabetizados na idade adulta obtiveram efeitos favoráveis de promoção cognitiva com a intervenção realizada.

Pode-se perceber que no grupo AA houve uma promoção cognitiva com o uso do roteiro em vários níveis do texto, com exceção dos detalhes. No grupo $\mathrm{AC}$ também se percebe uma promoção cognitiva com o uso do roteiro em vários níveis do texto, com exceção das inferências. A partir de uma organização externa do texto foi possível, provavelmente, a ativação de uma organização mental interna do texto.

O roteiro-guia, que demonstrava e exemplificava a identificação das estruturas do texto, serviu para desenvolver competências de monitoramento cognitivo para o aprimoramento da compreensão em ambos os grupos. Os sujeitos menos habilidosos, a partir desse monitoramento externo, conseguiram, provavelmente, organizar mentalmente o roteiro tradicionalmente exibido pelos textos (macroestru- 
tura, argumentação, detalhes, inferências) e, assim, esquematizando internamente esse roteiro, foram capazes de adaptar esta estrutura para uma melhor compreensão de outros textos que seguissem o mesmo esquema proposto. Ao internalizar a estrutura do texto, os sujeitos foram então capazes de desencadear esse esquema toda vez que ele foi ativado por uma nova fonte perceptiva ou representacional de forma a adequar o processamento dos argumentos e da ideia central do texto, assim como o de realizar o emparelhamento do conhecimento anterior com o conhecimento do texto, para o desencadeamento das inferências necessárias.

Yekovich e Walker (1986) (YEKOVICH; YEKOVICH, 1996), ao investigarem a recuperação de conceitos roteirizados da memória de texto episódica, mostraram que a organização do conhecimento roteirizado pré-existente influencia de modo previsível a composição e a recuperação de conceitos. Segundo esses autores, a memória de texto episódica é um traço composto que se forma quando as pessoas leem um texto que descreve a execução de uma atividade cotidiana ou roteirizada. A memória de texto episódica é composta de dois tipos de informação: a) as informações já conhecidas sobre o roteiro; b) as informações que são fornecidas pelo texto.

Ainda segundo esses autores, primeiro, o conhecimento de um roteiro consiste de componentes de memória processual e declarativa separados. A memória declarativa refere-se ao conhecimento factual que se tem de um roteiro, é uma rede semântica que inclui nós conceituais e conexões relacionais. Segundo, o processamento de um encapsulamento mnêmico depende do seu nível de ativação. Logo, a recuperação de um conceito de um traço de memória composta varia com o nível de ativação desse conceito. Contudo, o nível de ativação é influenciado por diferentes fatores, entre eles a organização da rede através da qual flui a ativação. Terceiro, a estratégia cognitiva empregada para a recuperação de conceitos mnêmicos afeta tanto a velocidade como a probabilidade de recuperação. Portanto, a recuperação de um conceito de traço da memória episódica varia com o nível de ativação sobre o conceito e com a estratégia de recuperação empregada.

O trabalho de Yekovich e Walker (1986) discute esses três pressupostos com relação ao conhecimento roteirizado. Ambos propõem uma estrutura hipotética de um roteiro para mostrar que a organização de fato influencia o nível de ativação de vários nós mnêmicos em um traço composto e também reveem duas estratégias de recuperação e mostram que essas estratégias produzem padrões de recuperação de conceitos roteirizados similares aos padrões de recuperação observados na aprendizagem experimental.

Assim, conforme os experimentos realizados por Yekovich e Walker (1986) (YEKOVICH; YEKOVICH, 1996), pode-se entender melhor que o conhecimento roteirizado consiste em uma ampla rede de associações declarativas junto com um poderoso conjunto de mecanismos processuais que operaram na estrutura 
declarativa. Logo, os conceitos e proposições roteirizados são processados como outros conceitos e fatos dentro de uma estrutura em rede. A componente processual do conhecimento roteirizado é sensível aos objetivos individuais e às condições da situação rotineira. Dessa forma, as contribuições desses pesquisadores e seus experimentos possibilitam um melhor entendimento da recuperação da informação através de roteiros.

Por fim, pode-se considerar que o fato de que o grupo AC não tenha apresentado diferença entre o pré e o pós-teste no nível inferencial seja porque pertencem ao universo letrado há mais tempo, uma vez que foram alfabetizados na infância. Este grupo está muito mais habituado a utilizar textos de diversas naturezas tendo que emparelhar adequadamente o seu conhecimento de mundo com o que é lido, tendo então, um bom desempenho neste nível de processamento do texto.

Quanto aos detalhes, para os estudantes alfabetizados na idade adulta é bastante razoável que não tenham obtido diferenças significativas entre o pré e o pós-teste, pois este nível é o menos relevante para a compreensão textual.

\section{Considerações Finais}

Este estudo revelou que leitores pouco habilidosos dos dois grupos de sujeitos foram privilegiados pela intervenção do pesquisador ao apresentar aos participantes um roteiro estruturado do texto e, ao exemplificar com eles essas estruturas, foram beneficiados por esta ajuda, o que permitiu, provavelmente, que um esquema mental se desenvolvesse para o tratamento do texto subsequente. Aprenderam a criar uma estratégia de monitoramento da compreensão que lhes auxiliou a promover sua própria compreensão.

Nesse sentido, o que se pode pensar como desdobramento destes resultados é que o papel que o professor desempenha diante de seus alunos é de fundamental importância. É ele quem vai mediar, intervir, instigar, contribuir e potencializar as atividades para que os educandos avancem na questão da compreensão da linguagem escrita. É ele que poderá propor roteiros de conhecimentos para os alunos e ativá-los de forma que possam desencadear múltiplos esquemas de compreensão e assim organizar as ideias centrais do texto, entender os argumentos e os temas subsidiários que sustentam o tema central. Estratégias de intervenção, como a proposta neste estudo, podem ser facilmente realizadas em sala de aula com o intuito de melhorar o desempenho dos alunos, no que se refere à compreensão de textos. 


\section{REFERÊNCIAS}

ANDRADE, M. W. C. L.; DIAS, M. G. B. Processos que levam à compreensão de textos. Psicologia em Estudo, v. 11, n. 1, p. 147-154, 2006.

BARIANI, I. C. D.; MARTINS, R. M. M.; SANTOS, A. A. A. Estilos cognitivos e compreensão leitora em universitários. Paidéia, v. 15, n. 30, p. 57-68, 2005.

BOTTINO, A. G. Compreensão da linguagem escrita na educação de jovens e adultos. 129p. Dissertação (Mestrado em Psicologia) - Universidade Gama Filho, Rio de Janeiro, 2004.

BRASIL. Ministério da Educação e do Desporto. Secretaria de Educação Fundamental. Educação de Jovens e Adultos. Brasília: Ação Educativa, 1998. (Coleção Viver, Aprender, v. I).

CUNHA, N. B.; SANTOS, A. A. A. Relação entre a compreensão da leitura e a produção escrita em universitários. Psicologia: Reflexão e Crítica, v. 19, n. 2, p. 237-245, 2006.

DIAS, M. G. B. B.; ROAZZI, A.; RODRIGUES, A. A. Raciocínio Lógico na compreensão de texto. Estudos de Psicologia, Natal, v. 7, n. 1, p. 117-132, 2002.

FERREIRA, S. P. A.; DIAS, M. G. B. B. A escola e o ensino da leitura. Psicologia em Estudo, n. 7, p. 39-49, 2002.

FERREIRO, E. Reflexões sobre alfabetização. São Paulo: Cortez, 2001.

FREIRE, P. A Importância do Ato de Ler - Em três artigos que se completam. 43. ed. São Paulo: Cortez Editora, 2002.

KINTSCH, W. Comprehension: A paradigm for cognition. Cambridge: University Press, 1998.

. Information accretion and reduction in text processing: Inferences. Discourse Processes, n. 16, p. 193-202, 1993.

. The role of knowledge in discourse comprehension: A construction model. Psychological Review, v. 95, n. 2, p. 163-182, 1988. 
McNAMARA, D. S. Reading Comprehension Strategies - Theories, Interventions and Technologies. Lawrence Erlbaum Associates, 2007.

OLIVEIRA, K. L.; SANTOS, A. A. A. Compreensão em leitura e avaliação da aprendizagem em universitários. Psicologia: Reflexão e Crítica, v. 18, n. 1, p. 118-124, 2005.

OLIVEIRA, K. L.; SUHEIRO, A. C. B.; SANTOS, A. A. A. Habilidades em compreensão da leitura: um estudo com alunos de psicologia. Estudos de Psicologia, Campinas, v. 21, n. 2, p. 29-41, 2004.

SANTOS, A. A. A.; SILVA, M. J. M. A avaliação da compreensão em leitura e o desempenho acadêmico de universitários. Psicologia em Estudo, v. 9, n. 3, p. 459-467, 2004.

SPINILLO, A. G.; MAHON, E. Compreensão de textos em crianças: comparações entre diferentes classes de inferência a partir de uma metodologia on-line. Psicologia: Reflexão e Crítica, v. 20, n. 3, p. 463-471, 2007.

STERNBERG, R. J. Psicologia Cognitiva. Tradução de: Maria Regina Borges Osório. Porto Alegre: Artes Médicas Sul, 2000.

VAN DIJK, T. A.; KINTSCH, W. Toward a model of text comprehension and production. Psychology Review, v. 85, n. 5, p. 363-394, 1983.

VILASECA, J. L. L. La Construcción de la Macroestructura: de la Compresión al Aprendizaje a partir de textos. In: MADRUGA, G.; GUTIÉRREZ, E.; GARATE, L. Comprensión lectora y memoria operativa. Aspectos evolutivos e instruccionales. Barcelona: Paidós, 1999. p. 1-56.

YEKOVICH, F. R.; WALKER, C. H. Retrieval of scripted concepts. Journal of Memory and Language, n. 25, p. 627-644, 1986.

YEKOVICH, F. R.; YEKOVICH, C. W. Assessing the progress of students in whole language classrooms. Washington, D.C.: ERIC Clearinghouse on Assessment and Evaluation, 1996.

Texto recebido em 28 de junho de 2010

Texto aprovado em 10 de agosto de 2010 